Journal of Engineering and Applied Sciences 14 (17): 6303-6311, 2019

ISSN: 1816-949X

(C) Medwell Journals, 2019

\title{
Applied Mckinsey 7S-Borda Method as an Assessment Model of Education System to Support Naval Technology Mastery
}

\author{
Supartono and I. Nengah Putra \\ Indonesia Defense University, Sentul, Sukahati, Citeureup, Bogor, 16810 West Java, Indonesia
}

\begin{abstract}
Implementation of a national defense strategy carried out at sea; relies on infrastructure and mastery of naval technology, especially on the Integrated Fleet Weapon System (SSAT). Indonesia Navy plans to develop an education and training system to support the mastery of naval technology. The study aims to formulate a measurement model the Indonesian Navy's education system to supporting the mastery of naval technology. This research uses Mckinsey 7S Framework and Borda method to determine the related criteria and give an assessment weight to these criteria. The resulting study presented Naval education system framework model consisted of 7 elements. From those elements, the highest element was structure with the weight of 0.073 . The second highest element was strategy with the weight of 0.071 . The strategy was followed by system as the element with the weight of 0.048 . Meanwhile, style had the weight of 0.034 and staff had the weight of 0.03 . Skill was the element with the weight of 0.017 . The last element was shared value with the lowest weight as much as 0.016. This research is expected to contribute and consideration of the Indonesia Navy in the development of Naval education system.
\end{abstract}

$\underline{\text { Key words: Naval education system, naval technology, Mckinsey 7S, Borda method, staff, education }}$

\section{INTRODUCTION}

Strategic environmental development in the field of technology requires mastery of technology, especially in naval technology. Development of Naval Technology (NT) has an impact on the modern military world and has changed the potential issue of "Military-Driven Information" to "Information Driven Millitary" (Edmunds et al., 2016). Implementation of a national defense strategy carried out at sea; relies on infrastructure and mastery of naval technology, especially on the integrated fleet weapon system (SSAT) (Yogi et al., 2017). Indonesia Navy plans to develop an education and training system to support the mastery of naval technology.

The study aims to formulate a measurement model the Indonesian Navy's education system to supporting the mastery of naval technology. This research uses Mckinsey 7S framework and Borda method to determine the related criteria and give an assessment weight to these criteria. This research is expected to contribute and consideration of the Indonesia Navy in the development of Naval Education System.

There is some literature related to this research such as a Mckinsey $7 \mathrm{~S}$ model to integrate key criteria on multi-organizational determinants and combines a set of key determinants (Rahmat and Ibrahim, 2018). Mckinsey $7 \mathrm{~S}$ model as a framework for the formulation of Business Intelligence and Big data analysis
(Jayakhrishnan et al., 2018). Mckinsey framework as an integrated model resource-based in industrial organizations (Baroto et al., 2014). Mckinsey framework as a determining factor in the implementation of supermarket strategies (Awino et al., 2017). Mckinsey framework uses to implement e-Learning system project (Alshaher, 2013). Development of the Mckinsey model as an assessment of Enterprise Resources Planning (ERP) readiness factors (Shiri et al., 2014). Mckinsey framework as a measurement scale for public sector company (Pothiyadath and Wesley, 2014). Mckinsey framework uses for integrating procurement system and assess compatible fields at the project level (Chong and Preece, 2014). Mckinsey uses for evaluating the impact of risk management at strategy implementation in comercial banking (Herbert et al., 2013).

Literatures explain about Borda method. Borda method as an assessment technique to determining district ranks (Moghimi and Yazdi, 2017). Borda as a rule of consistent weighting with pairing criteria between losers and winners (Okamoto and Sakai, 2013). Borda uses for evaluating synthesis ability of salesmen (Fang et al., 2017). Borda uses as integration of Multi Moora assessment models to evaluate excavator technology (Altuntas et al., 2015). Borda is used as a ranking aggregation approach model on query extensions (Singh and Sharan, 2015). Borda as a model of political economy weighting by considering the inter-time aspects (Ishida and Oguro, 2017).

Corresponding Author: Supartono, Indonesia Defense University, Sentul, Sukahati, Citeureup, Bogor, 16810 West Java, Indonesia 


\section{MATERIALS AND METHODS}

Naval technology: In conducting naval operations in the future, there is a need for highly skilled personnel with an effective response to an attack. In designing new systems and equipment, flexibility and adaptability are needed to manage technology improvements. In testing skills and providing training, there needs to be a closer relationship between Naval personnel and the defense industry to provide feedback on developing new capabilities (Shenoi et al., 2015).

The general trend towards fewer crews will encourage the application of technological capacity to improve crew capability. The role of warships by 2030 will begin to change with the use of unmanned systems and remote control systems. It will have a greater effect with less risk of the aircraft carrier. In addition, the need for mission flexibility and energy efficiency in naval vessels will encourage the application of technology which is related to energy storage, production, shipping and reuse or energy management (Shenoi et al., 2015).

In the Global Marine Technology Trends 2030 will focus on 8 technology fields with the potential to change naval operations in the future. These eight technologies will play an important role in future war battles (Shenoi et al., 2015). The eight technologies include advanced material, autonomus system, big data analytic, advanced manufacturing, energy management, cyber and electronic warfare, human computer interaction, human augmentation.

Naval education system: Development of human resources in the Navy is carried out through the process of education, assignment and training. Education system in Indonesia Navy consists of: basic training, regular education and advanced education. In advanced education. The advanced education for Navy officers consist of regular development, education, continuing education officers and Command and Staff College of the Navy. At the level of science and technology development aims to mastering science at the tactical level and strategic in bachelor level, masters level and doctoral level.

Development of the Navy's training is an activity to form, improve, maintain and test the ability of personnels and units in order to achieve operational readiness of the Navy. The purpose of training is to test doctrine and integrative. The training target includes the realization of the Navy's capabilities, namely intelligence capabilities, defense capabilities, security capabilities, regional empowerment capabilities, support capabilities.

\section{Education component}

Student: Students are an important element in higher education because of that it needs to be managed well in student management. Some indicators in student management in universities include: recruitment and selection systems for prospective students, student profile: academic, socio-economic, student involvement in various commissions; extra-curricular activities, sustainability of student recruitment, services for students, graduate competencies and ethics, learning outcomes, utilization of graduates and sustainability of the absorption of graduates, study program products.

Facilities and infrastructure: There are some facilities and infrastructure for higher education institutions needed to be completed. Those are related to; the management, the utilization and maintenance of facilities and infrastructure, the availability and quality of the buildings, lecture halls, laboratories and library, computer facility and learning and research support, conformity and sufficiency of facilities and infrastructure, the sustainability of procurement, maintenance and the utilization of facilities and infrastructure, the development design of information systems, sufficiency and conformity of the supported resources, facilities and infrastructure for the empowerment of information system, efficiency and effectiveness of the use of information system, the existence and the utilization of on-campus connectivity devices (intranets), the existence and the utilization of global connectivity devices (internet).

Financial: In general, the objectives of financial management of higher education institutions is done to meet the functions of financial management which are planning, budgeting, management, controlling, searching, storage and checking. The quality standards for the fund management of higher education institutes are seen from the following aspects: funding shortfall system; the management and the accountability on the use of funds; the sustainability of procurement and its use.

Curriculum: In higher education institutions, curriculum has to be planned, implemented and evaluated in a good and strategic manner. Curriculum is related to the three pillars of higher education of the following reasons: curriculum is related to the learning quality, curriculum is related to the research quality, curriculum is related to the community service quality.

Human resources: Higher education workforce is related to the management of human resources. Lecturers and employee's are human resources who have big roles as 
instructors and education staff. Human resources management is highly related to some issues such as learning, research and community service issues.

Mckinsey 7S Framework: McKinsey 7S Framework is a model created in early 1980's by Tom Peters and Robert Waterman (Alshaher, 2013). They were consultants who worked at McKinsey and Company consulting company. Since, then, Mckinsey 7S Framework had been used to analyze more than 70 big organizations. This framework consists of 7 variables which are easy to be understood and to be remembered. Those seven variables are strategy, structure, system, style, staff, skill and shared values (Alshaher, 2013). Those seven variables were categorized into two elements, hard and soft. Hard elements from $7 \mathrm{~S}$ Framework are easily defined variables such as strategy, structure and system. Meanwhile, soft elements are variables which are hardly defined such as style, staff, skill and shared values.

$7 \mathrm{~S}$ Framework is described as a group of related factors which support the ability of an organization to change. The point of this framework is that all those seven variables are related. Thus, a change in a variable needs a change in all variables to function effectively (Ravanfar, 2015). Because those factors maintain nonhierarchical relationship, it is impossible for organization to make a progress in one division only (Pothiyadath and Wesley, 2014). Therefore, McKinsey 7S Framework will help the organization to identify which factor needed to be aligned to improve the performance or to maintain the harmony during a change.

It is natural to have no hierarchy in the part of framework. However, the implementation of a factor will affect the other factors. Thus, a success of each part of the framework has to be carefully achieved. This framework had been built, since, more than 30 years ago. It has proven that many organizations believed that each part of an organization is not an isolated part of framework but a general unity for all level of organization instead. McKinsey 7S Framework can be described as follows (Ravanfar, 2015).

Shared values: The value of work culture that exists in the center of an organization. It is a guideline for each member of organization to grow and develop themselves.

Structure: The organizational structure is a reflection of organizational shared values made in order to optimally achieve the objectives of the organization. A structure which is able to reflect the shared values will well empower the organization to achieve the goals and objectives.
System: A system developed by the organization also, comes from the existing shared values. This system includes various things concerning planning, implementation, control and evaluation, budgets and awards.

Staff: Organization forms or manages its member or personnel based on the existing shared values. Organization will determine the terms and condition of people considered suit with the existence and the objectives of the organization. It is natural that the goals and objectives of the organization and its people can differ. Thus, it will be difficult for an organization to grow well in that condition.

Skills: The skills of each individual in the organization are very important for the success of the organization in achieving its goals and objectives effectively and efficiently. If the skills of the organizers of the organization are not in accordance with the needs of the organization to realize its vision, the organization will tend to be counter productive. Therefore, skills are the reflection of core competence of the organization because strategies that are prepared are also a reflection of the existing skills.

Style: The style of the organizational management (leadership) is a combination of the five previous elements. Those five elements determine the most appropriate leadership style in order to make the organization able to achieve its goals and objectives effectively and efficiently. Leadership style which does not meet those five elements will cause the organization to fail or lead to destruction.

Strategy: The strategy of an organization is intended to make the organization has clear and firm directions on its methods used to achieve the goals and objectives.

Borda method: Borda rules are included in the class of ranking rules in which points are awarded to each candidate or alternate according to rank in voter preferences (Caillaux et al., 2011). Each decision maker must order an alternate option according to the preference specified. One point is given to the highest choice alternative, the second received two points and so on (Mohajan, 2012) (Fig. 1 and 2).

In this method, if there are $n$ alternatives, the first choice of voters is given (m-1) points, the second point $(\mathrm{m}-2)$ and so on to the last option which is 0 points. Then, in each alternative, summaries of all points are given from all decision makers (or by criteria). The alternative is 
to rank in the order corresponding to the number, the fewer points gained, the better the alternate in the rankings. The formula describes as Junior et al. (2014):

$$
P_{a}=\sum_{i=1}^{n} r_{a 1}
$$

Where:

$\mathrm{P}_{\mathrm{a}}=$ The total number of points obtained by alternative a

$\mathrm{r}_{\mathrm{ai}}=$ The rank of alternative $\mathrm{a}$ in criterion $\mathrm{I}$

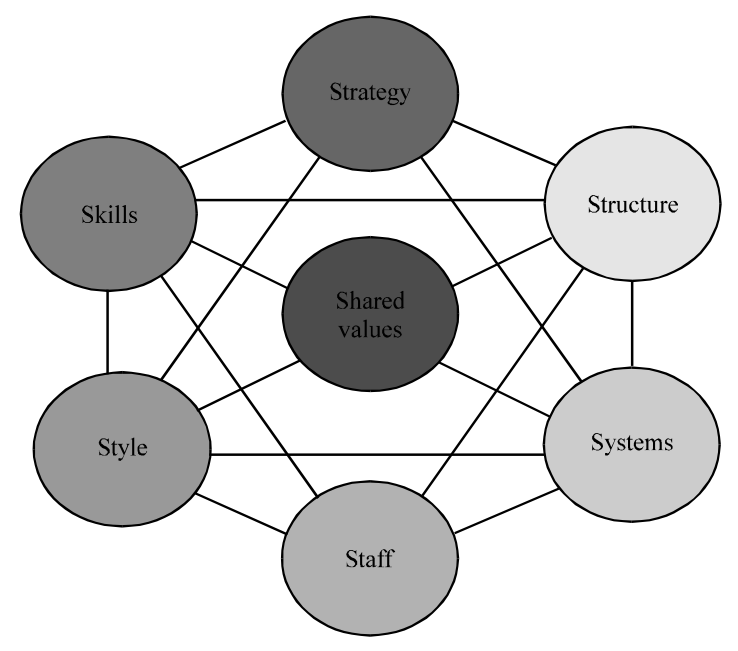

Fig. 1: Mckinsey 7S Framework (Alshaher, 2013)

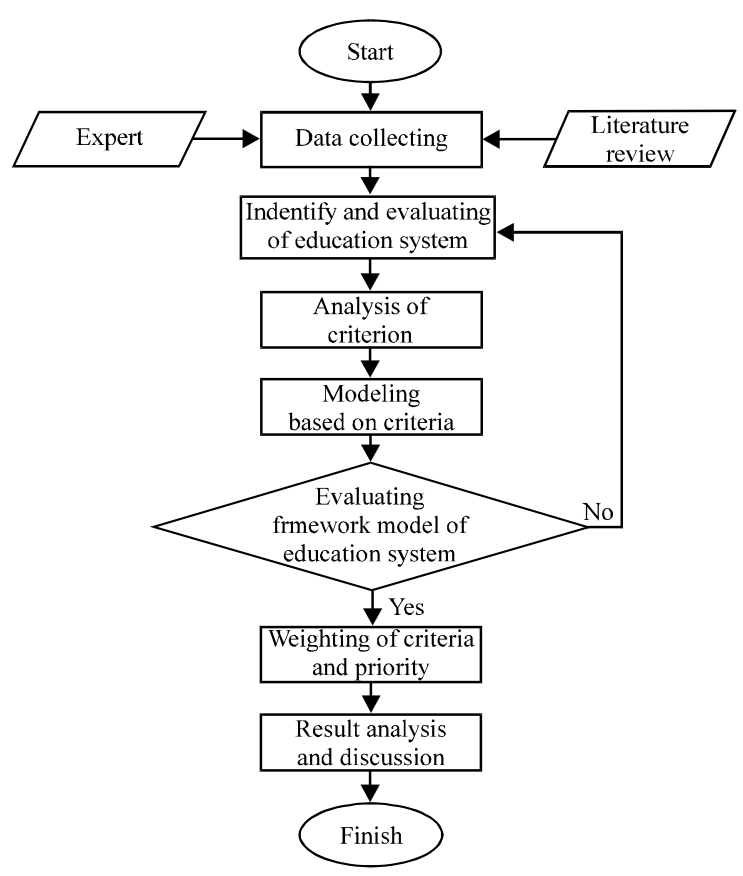

Fig. 2: Flowchart of Naval education system framework model
Objective: Determining criteria related to the educational system of Indonesian Navy in order to support technology mastery. Giving value of the related criteria and determining the priority in the strategy implementation.

\section{RESULTS AND DISCUSSION}

This study presents the results of the study of the measurement model of the education system of the Indonesian Navy. Those results were discussed to determine the readiness level for the development of the Indonesian Navy's education system and to reveal factors or criteria that are still considered weak. The data from observation and questionnaires were distributed to 6 experts (E1-E6). After that, the data were processed by looking for the criteria related to the education factor of the Indonesian Navy and the Mckinsey 7S Framework.

Criteria: The criteria for Indonesian Navy's education system development were set by integrating the components of higher education within the Mckinsey $7 \mathrm{~S}$ Framework. The criteria were set based on the observation results of the selected experts Fig. 3.

Second step: The criteria were set and given values using Borda method sorted by ranking. The given values were determined based on the consideration of the 6 selected experts. The output of this step is the value for each aspect and priority of the related aspects (Fig. 4).

Based on Table 1 and graph, vision had the highest value with 0.083 . This explains that every strategy

Table 1: Mckinsey aspect weight of naval education system

\begin{tabular}{lrcr}
\hline Criteria & Scores & Weight & Ranks \\
\hline Vision & 138 & 0.083 & 1 \\
Mission & 90 & 0.054 & 8 \\
Strategy plan & 130 & 0.079 & 2 \\
Centralization & 128 & 0.077 & 3 \\
Size & 116 & 0.070 & 5 \\
Formalization & 118 & 0.071 & 4 \\
IT infrastructure & 54 & 0.033 & 15 \\
Internal process & 85 & 0.051 & 10 \\
Data processing & 87 & 0.053 & 9 \\
Organization culture & 104 & 0.063 & 7 \\
Leadership & 63 & 0.038 & 13 \\
Top managemen support & 26 & 0.016 & 19 \\
Communication & 106 & 0.064 & 6 \\
Human resources management & 63 & 0.038 & 13 \\
Project team & 82 & 0.050 & 11 \\
Training and education & 23 & 0.014 & 20 \\
Management skill & 44 & 0.027 & 16 \\
IT staff skill & 76 & 0.046 & 12 \\
Teacher skill & 22 & 0.013 & 21 \\
Student skill & 8 & 0.005 & 23 \\
Value of employee confidence & 11 & 0.007 & 22 \\
Culture and organizational & 42 & 0.025 & 17 \\
Employee awareness & 40 & 0.024 & 18 \\
\hline
\end{tabular}




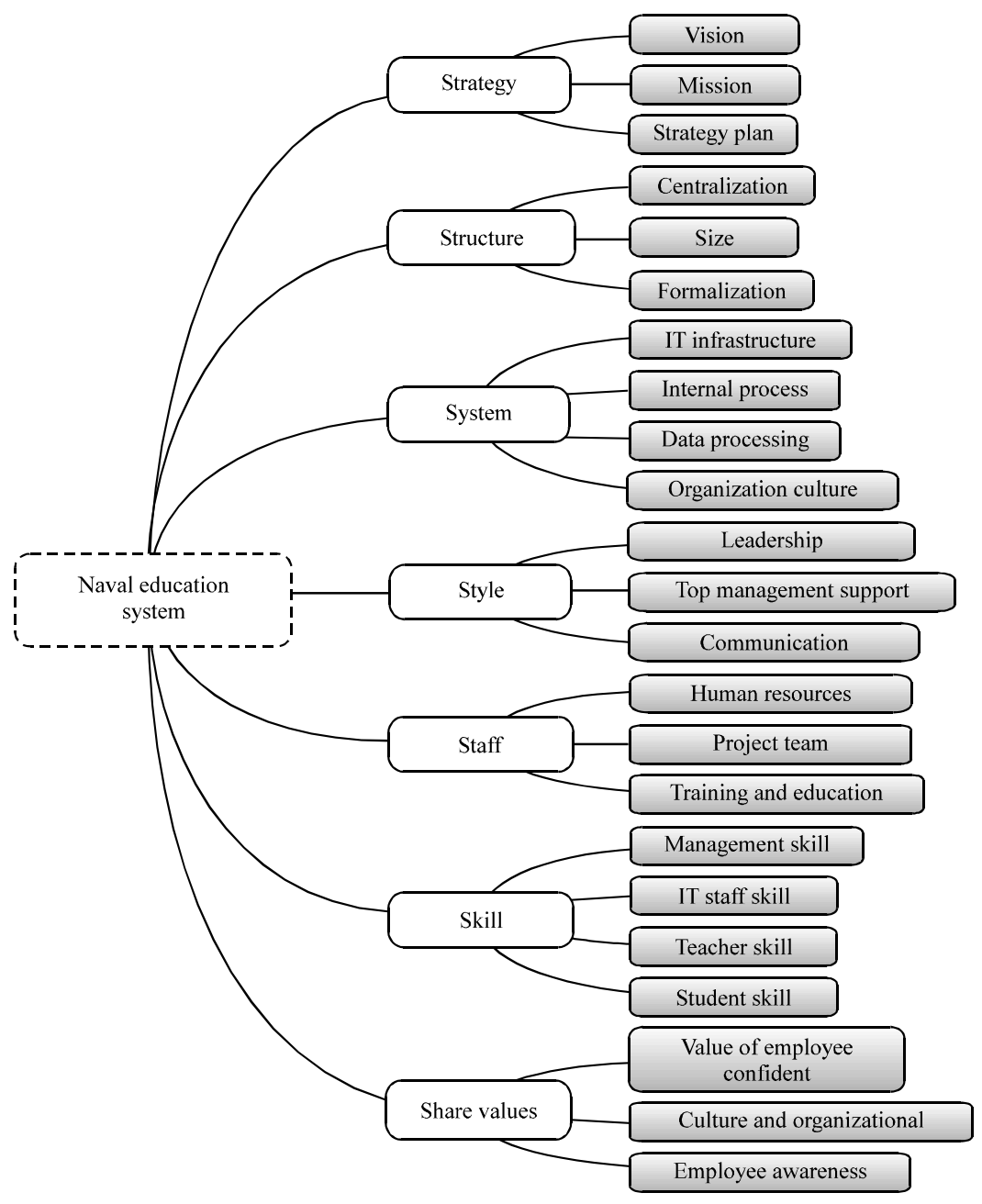

Fig. 3: Mckinsey model of Naval education system

Table 2. Weight of mckinsey element in naval education system

\begin{tabular}{lcc}
\hline Criteria & Weight & Ranks \\
Strategy & 0.071 & 2 \\
Structure & 0.073 & 1 \\
System & 0.048 & 3 \\
Style & 0.034 & 4 \\
Staff & 0.030 & 5 \\
Skill & 0.017 & 6 \\
Share values & 0.016 & 7 \\
\hline
\end{tabular}

was started with a vision. In this case, the vision of the Naval education system is "Professional and Modern Navy". Strategy plan ranked the second aspect with a weight of 0.079. Strategy plan is needed to describe the existing vision of the organization.

Based on the graph (Fig. 5) and Table 2, the structure was the highest element with a weight of 0.073 . Strategy was element with a weight of 0.071 placed second. System had the weight of 0.048 . Style had the weight of 0.034 . Staff had the weight of 0.03 . Skill has the weight of 0.017 . Shared value was the lowest element with the weight of 0.016 .
Table 3: Weight of strategy element

\begin{tabular}{lcc}
\hline Criteria & Weight & Ranks \\
\hline Vision & 0.083 & 1 \\
Mission & 0.054 & 3 \\
Strategy plan & 0.079 & 2 \\
\hline & & \\
Table 4: Weight of structure element & & Ranks \\
\hline Criteria & Weight & 1 \\
Centralization & 0.077 & 3 \\
Size & 0.070 & 2 \\
Formalization & 0.071 &
\end{tabular}

Strategy element: Based on the Table 3 , it can be inferred that vision was the highest aspect in strategy element with the weight of 0.083 . Mission had the weight of 0.054 while strategy plan had the weight of 0.079 . In this element, good vision and mission which were supported by good strategy plan were resulting output in form of good organization strategy.

Structure element: Based on the Table 4, centralization is the highest aspect in the structure element with the 


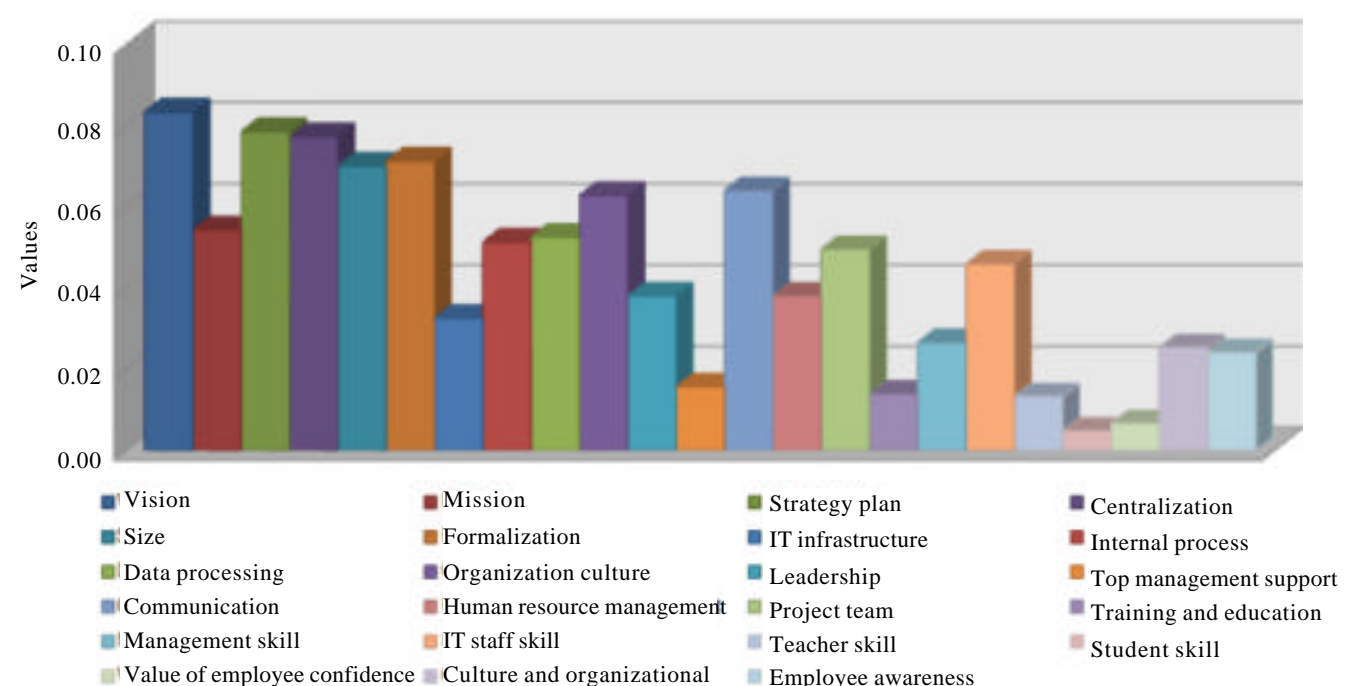

Fig. 4: Graph of Mckinsey aspect weight, weight value of Naval education system

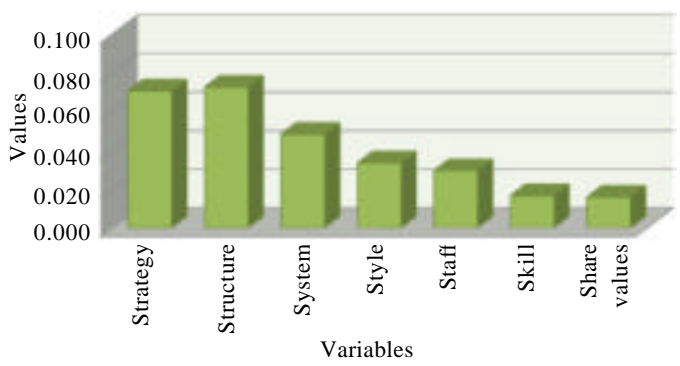

Fig. 5: Graph of Mckinsey element weight at Naval education system

weight of 0.077 . Size had the weight of 0.07 while formalization had the weight of 0.071 . In this element, good structure of organization supporting Naval education system consisted of three aspects which were centralization, size of organization and formalization of organization.

System element: In system element of Naval education system, there were four related aspects which were IT infrastructure, internal process, data processing and organization culture. Based on Table 5, in system element organization culture was the highest aspect with the weight of 0.063 . Data processing had the weight of 0.053 . Internal process had the weight of 0.051 . Meanwhile, IT Infrastructure had the weight of 0.033 .

Style element: In style element of Naval education system, there were three related aspects which were leadership, top management support and communication. Based on Table 6, communication was the highest aspect with the weight of 0.064 .
Table 5: Weight of system element

\begin{tabular}{lcc}
\hline Criteria & Weight & Ranks \\
IT infrastructure & 0.033 & 4 \\
Internal process & 0.051 & 3 \\
Data processing & 0.053 & 2 \\
Organization culture & 0.063 & 1 \\
\hline & & \\
Table 6: Weight of style element & Weight & Ranks \\
\hline Criteria & 0.038 & 2 \\
Leadership & 0.016 & 3 \\
Top managemen support & 0.064 & 1 \\
Communication & & \\
\hline & & Ranks \\
Table 7: Weight of staff element & Weight & 2 \\
Criteria & 0.038 & 1 \\
Human resourc es management & 0.050 & 3 \\
Project team & 0.014 & \\
Training and education & & \\
\end{tabular}

Meanwhile, the other aspects such as leadership and top management had the weight of 0.038 and 0.016 .

Staff element: Staff element of Naval education system had three related aspects which were human resources management, project team and training and education. Based on Table 7, staff element had the highest aspect which was project team with the weight of 0.050 . Meanwhile, human resources management and training and education had the weight of 0.038 and 0.014 .

Skill element: Skill element of Naval education system had four aspects which were management skill, IT staff skill, teacher skill and student skill. Based on Table 8, IT staff skill was the highest aspect in skill element with the weight of 0.046. Meanwhile, the other aspects such as management skill, teacher skill and student skill had the weight of $0.027,0.013$ and 0.005 . 
Table 8: Weight of skill element

\begin{tabular}{lcc}
\hline Criteria & Weight & Ranks \\
\hline Management skill & 0.027 & 2 \\
IT staff skill & 0.046 & 1 \\
Teacher skill & 0.013 & 3 \\
Student skill & 0.005 & 4 \\
\hline
\end{tabular}

Table 9: Weight of share values element

\begin{tabular}{lcc}
\hline Criteria & Weight & Ranks \\
\hline Value of employee confidence & 0.007 & 3 \\
Culture and organizational & 0.025 & 1 \\
Employee awareness & 0.024 & 2 \\
\hline
\end{tabular}

Share values element: Share values element of Naval education system had three aspects which were value of employee confidence, culture and organizational and employee awareness. Based on Table 9 share values had the highest aspect which was culture and organizational aspect with the weight of 0.025 . Management skill was an aspect with the weight of 0.027 . Employee awareness had the weight of 0.024 . Meanwhile, another aspect, value of employee confidence had the weight of 0.007 .

\section{CONCLUSION}

The implementation of the development strategy of the Naval education system was planned with Mckinsey framework model and Borda weighting method approaches. Naval education system framework model consisted of 7 elements. From those elements, the highest element was structure with the weight of 0.073 . The second highest element was strategy with the weight of
0.071 . The strategy was followed by system as the element with the weight of 0.048 . Meanwhile, style had the weight of 0.034 and staff had the weight of 0.03 . Skill was the element with the weight of 0.017 . The last element was shared value with the lowest weight as much as 0.016 .

Strategy element consisted of three aspects which were vision with the weight of 0.083 , mission with the weight of 0.054 and strategy plan with the weight of 0.079 . Structure element consisted of 3 aspects which were centralization with the weight of 0.077 , size with the weight of 0.07 , formalization with the weight of 0.071 . System element consisted of four aspects which were IT Infrastructure with the weight of 0.033 , internal process with the weight of 0.051 , data processing with the weight of 0.053 , organization culture with the weight of 0.063 . Style element had three aspects which were leadership with the weight of 0.038 , top management support with the weight of 0.016 , communication with the weight of 0.064 .

Staff element consisted of three aspects which were human resources management with the weight of 0.038 ; project team with the weight of 0.05 , training and education with the weight of 0.014 . Skill element had four aspects which were management skill with the weight of 0.027 , IT staff skill with the weight of 0.046 , teacher skill with the weight of 0.013 , student skill with the weight of 0.005 . Share values element had three related aspects which were value of employee confidence with the weight of 0.007 , culture and organizational with the weight of 0.025 and employee awareness with the weight of 0.024 .

\section{Appendix}

$\underline{\text { Result of questionnaire from expert }}$

\begin{tabular}{|c|c|c|c|c|c|c|}
\hline Criteria & E1 & $\mathrm{E} 2$ & E3 & $\mathrm{E} 4$ & $\mathrm{E} 5$ & $\mathrm{E} 6$ \\
\hline Vision & 1 & 1 & 1 & 1 & 1 & 1 \\
\hline Mission & 9 & 8 & 10 & 8 & 8 & 11 \\
\hline Strategy plan & 2 & 3 & 2 & 2 & 3 & 2 \\
\hline Centralization & 3 & 2 & 3 & 3 & 2 & 3 \\
\hline Size & 5 & 4 & 4 & 5 & 5 & 5 \\
\hline Formalization & 4 & 5 & 5 & 4 & 4 & 4 \\
\hline IT infrastructure & 15 & 15 & 15 & 15 & 15 & 15 \\
\hline Internal process & 10 & 11 & 11 & 10 & 9 & 8 \\
\hline Data processing & 8 & 10 & 9 & 9 & 12 & 9 \\
\hline Organization culture & 6 & 7 & 7 & 6 & 7 & 7 \\
\hline Leadership & 13 & 13 & 14 & 14 & 13 & 14 \\
\hline Top management support & 19 & 20 & 20 & 19 & 21 & 19 \\
\hline Communication & 7 & 6 & 6 & 7 & 6 & 6 \\
\hline Human resources management & 14 & 14 & 13 & 13 & 14 & 13 \\
\hline Project team & 12 & 9 & 8 & 12 & 11 & 10 \\
\hline Training and education & 21 & 19 & 21 & 20 & 19 & 21 \\
\hline Management skill & 16 & 16 & 17 & 18 & 17 & 16 \\
\hline IT staff skill & 11 & 12 & 12 & 11 & 10 & 12 \\
\hline Teacher skill & 20 & 21 & 19 & 21 & 21 & 20 \\
\hline Student skill & 22 & 23 & 23 & 22 & 23 & 23 \\
\hline Value of employee confidence & 23 & 22 & 22 & 23 & 22 & 22 \\
\hline Culture and organizational & 17 & 18 & 16 & 17 & 16 & 18 \\
\hline Employee awareness & 18 & 17 & 18 & 16 & 18 & 17 \\
\hline
\end{tabular}




\section{Compilation score from Borda method}

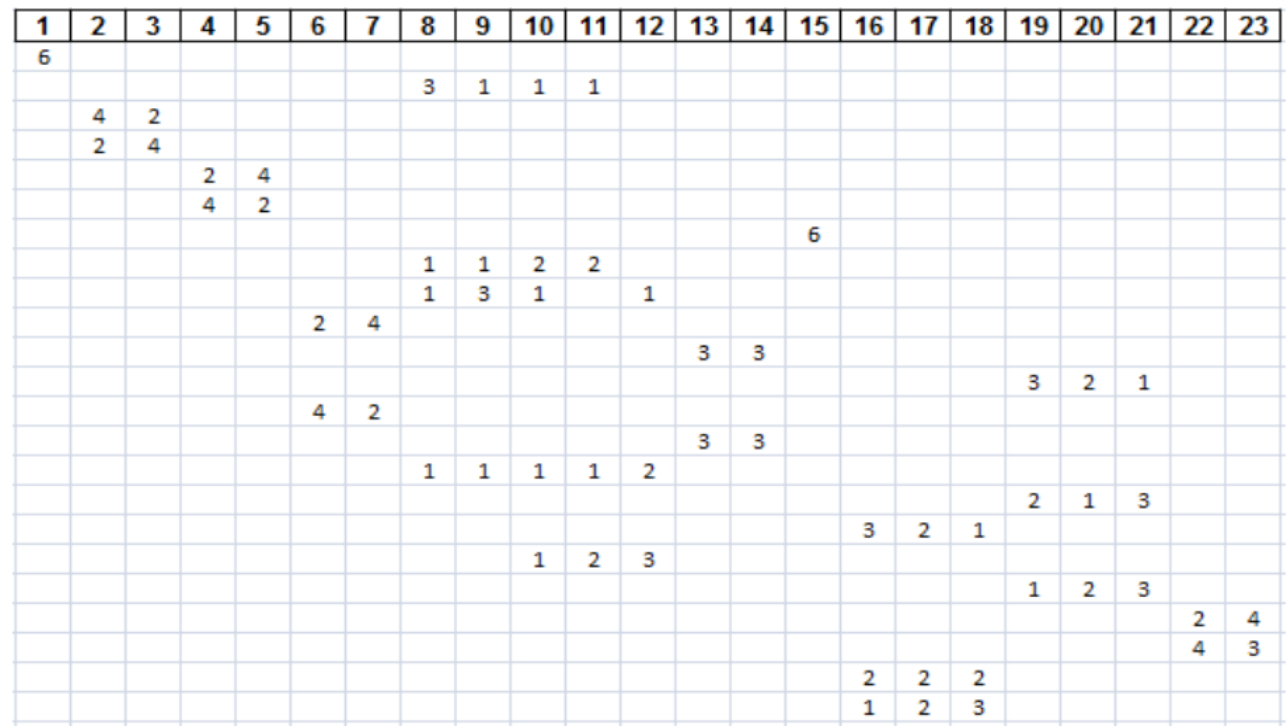

\section{REFERENCES}

Alshaher, A.A.F., 2013. The Mckinsey 7S model framework for E-learning system readiness assessment. Int. J. Advances Eng. Technol., 6: 1946-1966.

Altuntas, S., T. Dereli and M.K. Yilmaz, 2015. Evaluation of excavator technologies: Application of data fusion based MULTIMOORA methods. J. Civil Eng. Manage., 21: 977-997.

Awino, Z.B., W.G. Njeru and K. Adwet, 2017. Strategy implementation: Mckinsey's 7S framework configuration and performance of large supermarkets in Nairobi, Kenya. Arch. Bus. Res., 5: 1-17.

Baroto, M.B., N. Arvand and F.S. Ahmad, 2014. Effective strategy implementation. J. Adv. Manage. Sci., 2: 50-54.

Caillaux, M.A., A.P. Sant'Anna and L.A. Meza, 2011. Container logistics in Mercosur: Choice of a transhipment port using the ordinal Copeland method, data envelopment analysis and probabilistic composition. Marit. Econ. Logist., 13: 355-370.

Chong, H.Y. and C.N. Preece, 2014. Improving construction procurement systems using organizational strategies. Acta Polytech. Hungarica, 11: 5-20.

Edmunds, T., A. Dawes, P. Higate, K.N. Jenkings and R. Woodward, 2016. Reserve forces and the transformation of British military organisation: Soldiers, citizens and society. Defence Stud., 16: 118-136.

Fang, J., F. Xiang and Z. Zhen, 2017. Sales performance evaluation based on borda method. Intl. J. Investment Manage. Financial Innovations, 3: 67-70.
Herbert, M.O., W.O. Bichanga, F. Ngati and M. Loki, 2013. Effects of risk management components on strategic implementation by commercial Banks in Kisii town, Kenya. Intl. J. Econ. Commerce Manage., 2: $1-16$.

Ishida, R. and K. Oguro, 2017. Borda Count Method for Fiscal Policy-A Political Economic Analysis. Research Department Policy Research Institute, Tokyo,

Jayakhrishnan, M., A.K.B. Mohammad and M.B.M. Yusof, 2018. The holistic view of Bussiness Intelligent (BI) and Big Data Analysis (BDA) toward designing strategic performance management framework: A case study. J. Theor. Appl. Inf. Technol., 96: 2025-2045.

Junior, S.G., J.S. De Mello and L.A. Meza, 2014. Sequential use of ordinal multicriteria methods to obtain a ranking for the 2012 Summer Olympic Games. WSEAS. Trans. Syst., 13: 223-230.

Moghimi, M. and M.T. Yazdi, 2017. Applying Multi-Criteria Decision-Making (MCDM) methods for economic ranking of Tehran-22 districts to establish financial and commercial centers. Urban Econ. Manage., 5: 43-55.

Mohajan, H., 2011. Majority judgment in an election with Borda majority count. Intl. J. Manage. Transf., 6: 19-31.

Okamoto, N. and T. Sakai, 2013. The Borda rule and the pairwise-majority-loser revisited. Master Thesis, Keio University, Tokyo, Japan.

Pothiyadath, R. and J.R. Wesley, 2014. Developing a measurement scale for 7-S framework. IOSR. J. Bus. Manage., 16: 14-16. 
Rahmat, A.B. and C.K.I.C. Ibrahim, 2018. Improving multi-organizational team integration using organizational strategies. Proceedings of the 2018 International Conference on Industrial Engineering and Operations Management, July 26-27, 2018, IEOM Society International, Paris, France, pp: 921-932.

Ravanfar, M.M., 2015. Analyzing organizational structure based on 7s model of McKinsey. Global J. Manage. Bus. Res., 1: 43-55.

Shenoi, R.A., J.A. Bowker, A.S. Dzielendziak, A.K. Lidtke and G. Zhu et al., 2015. Global Marine Technology Trends 2030. University of Southampton, Southampton, UK., ISBN:13-978-0993372001, Pages: 186.
Shiri, S., A. Anvari and H. Soltani, 2014. An assessment of readiness factors for implementing ERP based on agility (extension of Mckinsey $7 \mathrm{~S}$ model). Intl. J. Manage., Accounting Econ., 1: 229-246.

Singh, J. and A. Sharan, 2015. Relevance feedback based query expansion model using Borda count and semantic similarity approach. Comput. Intell. Neurosci., 2015: 1-13.

Yogi, P., O. Rizal, S. Ahmadi and O.S. Suharyo, 2017. Feasibility analysis of naval base relocation using SWOT and AHP method to support main duties operation. J. Defense Manage., 8: $1-8$. 